\title{
FLYING SCHEDULE-MATCHING DESCENTS TO EXPLORE FLIGHT CREWS' PERCEPTIONS OF THEIR LOAD AND TASK FEASIBILITY
}

\author{
Lynne Martin, San Jose State University at NASA ARC, Mountain View, CA \\ Shivanjli Sharma, Stinger-Ghaffarian Technologies at NASA ARC, Mountain View, CA \\ Sandra Lozito, John Kaneshige, Miwa Hayashi, NASA Ames Research Center, Mountain View, CA \\ Victoria Dulchinos, San Jose State University at NASA ARC, Mountain View, CA
}

\begin{abstract}
Multiple studies have investigated the development and use of ground-based (controller) tools to manage and schedule traffic in future terminal airspace. No studies have investigated the impacts that such tools (and concepts) could have on the flight-deck. To begin to redress the balance, an exploratory study investigated the procedures and actions of ten Boeing-747-400 crews as they flew eight continuous descent approaches in the Los Angeles terminal airspace, with the descents being controlled using speed alone. Although the study was exploratory in nature, four variables were manipulated: speed changes, route constraints, clearance phraseology, and winds. Despite flying the same scenarios with the same events and timing, there was at least a 50 second difference in the time it took crews to fly the approaches. This variation is the product of a number of factors but highlights potential difficulties for scheduling tools that would have to accommodate this amount of natural variation in descent times. The primary focus of this paper is the potential impact of ground scheduling tools on the flight crews' performance and procedures. Crews reported "moderate to low" workload, on average; however, short periods of intense and high workload were observed. The non-flying pilot often reported a higher level of workload than the flying-pilot, which may be due to their increased interaction with the Flight Management Computer, when using the aircraft automation to assist with managing the descent clearances. It is concluded that ground-side tools and automation may have a larger impact on the currentday flight-deck than was assumed and that studies investigating this impact should continue in parallel with controller support tool development.
\end{abstract}

\section{Study Background and Motivation}

In today's air traffic system, an aircraft flying through a busy terminal area can expect to be given multiple speed changes, altitude level-offs, and/or heading vectors. Although positive Air Traffic Control (ATC) results in a very safe system, it is often not efficient for a single flight. When demand is low, there is more space between aircraft and controllers have flexibility to descend aircraft along an efficient descent profile. When demand is high, traffic density often constrains the availability of these profile descents.

The Airspace Technology Demonstration (ATD1) concept developed by NASA [1] aims to safely sustain high runway throughput while also enabling fuel-efficient operations. Research is being undertaken in advanced scheduling capabilities that create schedules at the runway to enable aircraft to fly Optimized Profile Descents (OPDs) along Area Navigation (RNAV) routes [2]. Aircraft on these descents will be cleared to the runway and then will be able to rely on speed to maneuver as they fly into and through the terminal area. This will allow an aircraft to maintain its place in a tightly packed stream by meeting its scheduled time of arrival (STA). The STA is allocated prior to top-of-descent by the ground-based scheduling system. Assuming en route controllers feed the Terminal Radar Approach Control (TRACON) with a reasonable flow, that is, within certain tolerances of the schedule, TRACON controllers would rely primarily on speed adjustments to bring aircraft through the TRACON [3]. The benefit to aircraft is a smooth, low energy descent that is fuel efficient and faster.

Controller-Managed Spacing (CMS) research in the Airspace Operations Laboratory [4] has conducted a series of real-time human-in-the-loop simulations to investigate specific controller decision support tools (DSTs) for such operations. With relatively straight-forward display enhancements, TRACON controllers were able to manage dense arrival flows that followed OPDs along RNAV routes and met runway schedule times without significant increases in their workload (see [5] and [6] for accounts of this research). 
One set of assumptions within the ATD1 concept, and for the relevant research to date, is that these schedule-based, RNAV OPDs will have minimal impact on the flight deck. This encompasses primarily three sub-assumptions: firstly, that flight crews will be able to fly these descents and meet the speed instructions issued to them; secondly, that they will be able to do this without significant increases to their workload; and thirdly, that no training is required. This last assumption is based on reasoning that the route (lateral coordinates) of an OPD RNAV descent is almost the same as current day Standard Terminal Arrival Routes (STARs). In addition, altitude and speed constraints are common today, although not nearly as numerous as they will be in the future if schedule-based descents are implemented. Hence, it has been an assumption that flight crews will be able to manage these schedulebased clearances without additional training.

The present study was undertaken to explore the above assumptions; that is, to ascertain the crews' ability to fly schedule-based OPDs with no prior training and to examine their workload level and aircraft management strategies.

A secondary driver for this study was to explore the variation in, or range of, speeds that are acceptable to an airplane crew throughout their descent, and to inform the CMS tools regarding where and what limits should be set within the automation [7]. Current work exploring flight-deck interval management (FIM) [8] constrains the FIM automation, when used by airplane crews to control their descent, to issuing speeds within a ten percent deviation from the current speed. It is unknown whether the ground-based CMS tools should also adhere to a ten percent speed deviation in their advisories or whether larger deviations would be acceptable to, and flyable by, flight crews. The advantage of larger speed changes is that the automation would be able to solve bigger schedule mismatches using speed alone. To intentionally explore the outer limits of acceptable speed variations, it was determined that twenty percent deviations to the pre-determined speed profile would be presented in this flight deck simulation.

\section{Method}

The study described in this paper was exploratory and broad, encompassing multiple factors of human-computer interaction, including workload, crew procedures, and the use of automation tools. The study was designed to address a number of variables but the number of conditions explored within each variable was limited to permit a full cross-comparison. Using the same airspace employed in the CMS studies, the TRACON around Los Angeles International Airport (LAX), and flying two of the same routes was deliberate to allow data to be compared if this was desirable at a later point. As the key assumptions under investigation were human factors issues, the simulation facility with the greatest level of realism of those available was selected.

\section{The Simulation Facilities}

The study was flown in a Boeing-747-400 simulator [9] at the NASA Ames Research Center. It is a certified FAA Level D simulator and has the same cab configuration as a United Airlines flight deck (a 747-422 variant). The simulator compartment includes the cockpit flight deck, observer seats and an experimenter operator control station. The weight and balance of the simulator was configured for this study to have an overall simulated weight of 540,000 pounds - in the mid range for this aircraft type. The "motion", the hydraulic system that creates a sense of moving forward when inside the cab, was turned on, giving the participants some level of kinesthetic and vestibular feedback. The additional traffic was generated by the Multi Aircraft Control System (MACS) software [10], which also generated the Air Traffic Controller's screen and schedule. The controller used the schedule only to separate traffic and not to meet the aircraft STAs in this study. The two simulations were connected through a Higher Level Architecture that exchanged data to show the B-747 simulator on the controller's screen and the traffic on the displays inside and out of the windshield in the cab.

\section{Participants}

Twenty active pilots, all currently flying for one of four carriers operating under CFR 14 Part 121 (commercial), and all certified to fly a B-747, took part in the study as ten two-person crews. Co-crewmembers were paired from the same carrier to ensure that the team could work to the same set of procedures, although these procedures differed across crews/ carriers. The participants were highly 
experienced, having a mean of 16,288 flight hours each.

\section{Routes and Airspace}

Each crew flew eight approaches through the Los Angeles Terminal Area (SOCAL) into LAX. Two arrival routes were used, one from the northwest to the 24-Right runway and one from the east to the 25-Left runway. The routes map closely onto the existing SADDE and RIIVR Standard Terminal Arrival Routes. The actual routes used had been built for the prior ground-side studies [5] to allow the aircraft to fly optimized profile descents on an RNAV/RNP (Required Navigation Performance) adaptation, giving the routes a continuous descent profile (CDA) from cruise altitudes through the STARs to the runway threshold. That is, the STAR, transition, and ILS approach were linked into one route from top to bottom of the descent. In the ground automation studies, all the routes were characterized by hard altitude and speed constraints at multiple waypoints through the airspace. However, in the present study these hard constraints were only kept for the SADDE route, which had hard altitude and speed constraints at five waypoints (DEANO, SADDE, CULVX, HUMEL and JETSA) (Figure 1). Thus, the SADDE route was flown in exactly the same way as in earlier CMS simulations [5]. The RIIVR STAR was partially converted back to a more 'current day' variant of the route, with three window altitude constraints (at GRAMM, HABSO and RIIVR) (Figure 1 also), although four speed constraints were kept (at GRAMM, LUVYN, FUELR and GAATE).

To present the routes to the participants, these speed and altitude constraints were added to currently available arrival plates of the routes. Participants were given a set of these reference charts that showed the nominal speed and altitude profiles for the study and the distances between waypoints.

The simulator was initialized 135 nautical miles (nmi) from the runway on both routes, putting it a few miles before the Top-of-Descent; it was always initialized at $28,000 \mathrm{ft}$ and at 300 knots. Participants flew the RIIVR2 STAR to runway 25L four times and the SADDE7 STAR, with a base turn, to land on runway $24 \mathrm{R}$ four times. The scenario began with the crew receiving a descent clearance that cleared them to descend on the route to the runway. During each of the runs, the speed scenario that was presented, the phraseology used, and the winds were varied.

\section{Winds}

The same forecast wind profile was used for all runs. Beginning at around 60 knots at $28,000 \mathrm{ft}$, the strength of the wind gradually decreased to 7 knots at the runways. The wind was always out of $265^{\circ}$, a headwind aligned with the landing runways. This was the wind profile entered into the flight plan and the profile from which the simulator's FMS (Flight Management System) calculated the aircraft's descent profile. In half of the runs, the actual winds that the simulator flew in were the same as the forecast winds. In the other half of the runs, the simulator flew in actual winds that were ten knots greater than the forecast winds between $20,000 \mathrm{ft}$ and 1,500ft. Above and below these altitudes, the actual winds remained the same as the forecast winds.

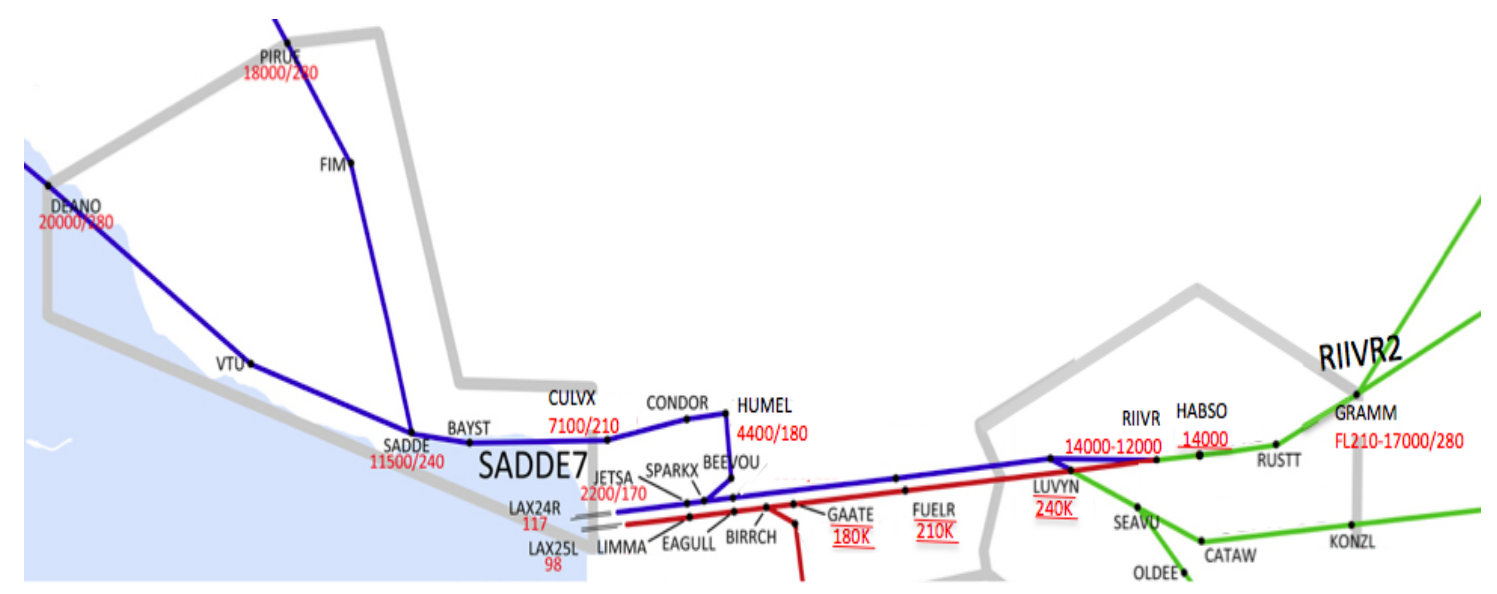

Figure 1. Routes flown in SOCAL airspace 


\section{Speed Schemes}

To test the boundaries of speed variations that are acceptable, this study explored a twenty percent deviation of speed clearances around the profile speeds that had been created for the controller automation studies [6]. The nominal speed profiles were developed by [6] to enable continuous descents that would allow aircraft to meet their STAs at the outer marker. They are a series of hard speed constraints that decelerate aircraft on the route through $280,240,210$ and 180 or 170 knots to the outer marker. As an aside, if pilot participants followed this series of speed reductions the aircraft would meet the current FAA regulation to be flying at less than 250 knots below 10,000 ft MSL. As this study explored a twenty percent variation from the nominal profile speeds, crews were asked to fly as fast as 340 knots (20\% over 280 knots) to the first waypoint, on the TRACON boundary, and as slow as 160 knots at HUMEL and GAATE. (160 knots was only $11 \%$ less than 180 knots (not $20 \%$ ) but was considered to be the lowest acceptable speed over these waypoints.)

Two speed schemes were created that each had two cycles of speed variation. One scheme was a "fast-to-slow" profile, where a faster speed than the profile was issued first (e.g., 340 knots), followed by the profile speed (e.g., 280 knots), then a speed slower than the profile speed was given (e.g., 220 knots). The second scheme was a "slow-to-fast" profile, where a slower speed than the profile was given first, followed by the profile speed, then a speed faster than the profile speed was issued. This second speed scheme created a number of points of interest, namely asking for 220 knots above $20,000 \mathrm{ft}$, which is a "dirty" speed for the B-747 - a speed that is slow enough that a crew would normally deploy flaps; and then asking for the same speed, which is relatively fast, for the last $15 \mathrm{nmi}$ before the outer marker.

\section{Phraseology}

The phraseology used in the study was manipulated to compare a variant that had been developed in previous ground-side studies [6] with current day phraseology. "Current day" speed clearances were characterized as single-item transmissions that instructed a crew to increase or decrease their speed some number of indicated knots.
"Future CMS" speed clearances contained two items. They instructed crews to increase or decrease their speed away from the profile speed (written on the chart constructed for the study) but also told them where they could resume the speed profile (based on the chart) using the phrase "until". For example, the controller issued a clearance: "Increase speed to 340 until DEANO, then resume published speeds." This clearance instructed the crew to increase their speed from their present speed of 300 knots to 340 knots and stay at this speed until close to the waypoint DEANO, when they should slow to the speed shown on the chart to cross DEANO at 280 knots. In the current day condition, the controller issued a first clearance to "increase speed to 340" followed by a second clearance close to DEANO to "reduce speed to 280." So, twice as many speed clearances were issued in the current day phraseology condition compared to the future-CMS condition, generating twice as many speed transmissions, but the clearances in the future-CMS condition were longer. Although the two conditions differed in their phrasing of the speed clearances, exactly the same increases and reductions were given in both conditions.

\section{Study Design}

The variables for the study were the speed scheme used, the phraseology type used and the type of constraints (routes) flown. Each variable had two conditions, e.g., the phraseology was either "current day" or "future CMS". This generated a $2 \times 2 \times 2$ matrix (2 phraseology $x 2$ speed scheme $x 2$ constraint type) that translated to eight Scenarios representing each cell of the matrix. These eight scenarios were each presented once to each crew in a semi-random order. (A randomized matrix was adjusted to ensure that no Scenario occupied the same place in the run order too often.) Additionally, a crew flew half of their Scenarios with actual winds equaling forecast winds and the other half with actual winds being 10 knots greater than forecast winds.

Crews participated in the study for one day. They were briefed in the morning and given time to review the charts and discuss their procedures and "flight plan" as a crew. They were specifically not given a chance to fly a training run to meet the assumptions of the concept. Crews flew four runs before lunch and four after, with each run taking 
approximately 35 minutes. There was a 10 to 15 minute break between each scenario.

\section{Data Collection}

Data were recorded for each run through a variety of media. The B-747 simulator's data collection logs recorded all flight parameters and cab flight-panel button states. A Voice-Over-InternetProtocol system recorded the crew-controller communications, and in-cab video equipment recorded flight-deck conversations and four views of the general cab environment and the flight displays. Participants were asked to respond to a real-time workload prompt, using an ATWIT-based procedure [11], that was recorded on a stand-alone laptop and observers recorded flight crew actions using a penciland-paper scheme. MACS' data collection logs recorded an Air Traffic Controller view of each run. Following each run, the participants completed a onepage questionnaire that included questions about their workload and problem solving. At the end of the study, participants completed a longer questionnaire asking more generic questions about the concept, and took part in a short debriefing discussion.

In addition, the research team flew the same eight descents with the same clearances, specifically trying to maintain the vertical profile of the descent. All the same data $\operatorname{logs}$ as for the study crews were collected but none of the subjective data. The research team's data is labeled "baseline" below. The following section describes results from a sample of the analyses conducted thus far.

\section{Results}

As noted above, the aims of the study were exploratory: to document how flight deck crews managed requests for large speed changes while on a CDA and to gain feedback about the workload involved and the acceptability of the clearances.

\section{Feasibility}

Of the 80 approaches flown, three were excluded from the data because a simulator artifact or pilot error meant the crew did not complete the flight. Of the remaining 77 approaches, 75 (97\%) were completed with the crew landing on their assigned runway at LAX. In two of the flights, the crew elected to perform a missed-approach because they were not stable on the approach at the designated position according to their company procedures. In these two instances, although the routes and winds for the runs were different, the future-CMS phraseology was being used and the speed scheme was slow-to-fast, so the crews were trying to reduce their speed from 220 knots to around 150 knots in less than $11 \mathrm{nmi}$.

The time it took crews to fly the approaches was explored to investigate the potential implications of the aircraft performance variation upon ground scheduling algorithms. The 77 approaches, from the point when the first speed clearance was given to the aircraft flying over the outer marker (JETSA or LIMMA), varied by three minutes - from $17 \mathrm{~min}$ $26 \mathrm{sec}$ to $20 \mathrm{~min} 29 \mathrm{sec}$. Figure 2 plots the fastest and the slowest descent for each of the eight scenarios that crews flew. Although the SADDE route with the procedure turn was five miles longer between the first speed clearance and the outer marker, it took less time to fly, with the slowest flight time being $19 \mathrm{~min}$ $25 \mathrm{sec}$ and the fastest time being $17 \mathrm{~min} 26 \mathrm{sec}$, a variation of two minutes in the time to fly the descent. The RIIVR route had a fastest flight time of $17 \mathrm{~min} 35 \mathrm{sec}$ and a slowest flight time of $20 \mathrm{~min}$ $29 \mathrm{sec}$, a slightly larger variation of $2 \mathrm{~min} 53 \mathrm{sec}$. What is striking about these times is not their absolute value but the size of their variation considering that the conditions (route and clearances) were the same for each crew in each scenario.

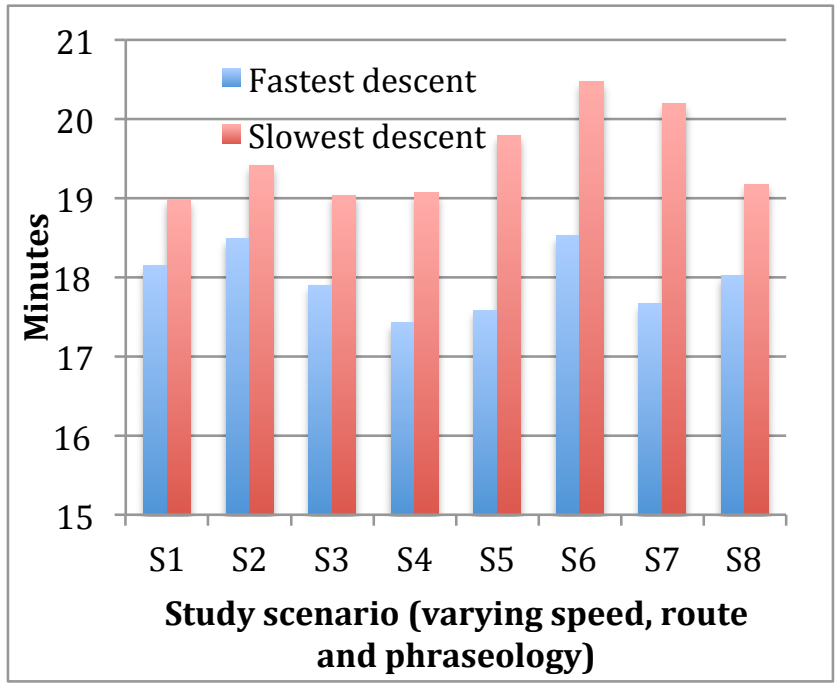

Figure 2. Fastest and Slowest Flight Times for Each Route 
Of the eight scenarios presented, Scenariol had the least variation (only 50 seconds) in the time it took the ten study crews to fly it. This scenario was on the SADDE route and combined the future CMS phraseology with a fast-to-slow speed scheme. Due to its hard constraints and conditional phraseology, this was ranked by the research team as one of the harder Scenarios to fly of the set. Scenario 7 had the greatest variation $(2 \mathrm{~min} 32 \mathrm{sec})$ in the time it took study crews to fly its descent. This scenario was physically the opposite of Scenariol as it was on the RIIVR route with a slow-to-fast speed scheme. The only similarity between the two scenarios was the phraseology the Air Traffic Controller used to issue the speed clearances, which was the future-CMS format. It could be that some combination of window constraints and/or a slow-to-fast speed scheme increases the variability in the methods crews used to fly the approach.

The baseline crew took the longest to fly three of the four RIIVR scenarios, with the exception of Scenario7. The baseline crew also took the shortest time to fly three of the four SADDE scenarios, with the one exception for the SADDE routes being Scenario1. In general, therefore, the baseline crew, who knew the scenarios and whose strategy was to maintain their vertical profile over other parameters, provide the upper timing boundary for the RIIVR route and the lower timing boundary for the SADDE route. This does not refute the possibility that a variation in crew methods leads to different descent times but adds an interesting finding that, in general, strategy variations led to participant-crews descending faster than the baseline crew on the RIIVR route and slower than the baseline crew on the SADDE route.

Figure 3 shows the indicated airspeed (IAS / calibrated airspeed) flown by each crew, from the point of the first speed clearance to the runway, in Scenario1 and Scenario7. The graph for Scenario1 (Figure 3a) shows that, except for a period when they received two speed reductions (between approximately 70 to $50 \mathrm{nmi}$ from the runway), crews were flying close to the same speeds at the same distances from the runway, e.g., close to 220 knots at $40 \mathrm{nmi}$ out. This essentially means that their descents were more uniform in terms of speed, and hence time. The graph for Scenario7 (Figure 3b) provides a contrast and some explanation for the greater variation in the time it took crews to fly this Scenario. In this graph there are far fewer points where crews were flying close to the same speeds at the same distance from the runway. In this graph, the point where all crews were flying close to 290 knots at 40 $\mathrm{nmi}$ out is an exception. More representative is the point $10 \mathrm{nmi}$ before, at $50 \mathrm{nmi}$ from the runway, where there is more than a 40-knot difference in the speeds crews were flying at the same point in the run. For this Scenario, crew descents were diverse, or nonuniform in terms of speed, and hence time.

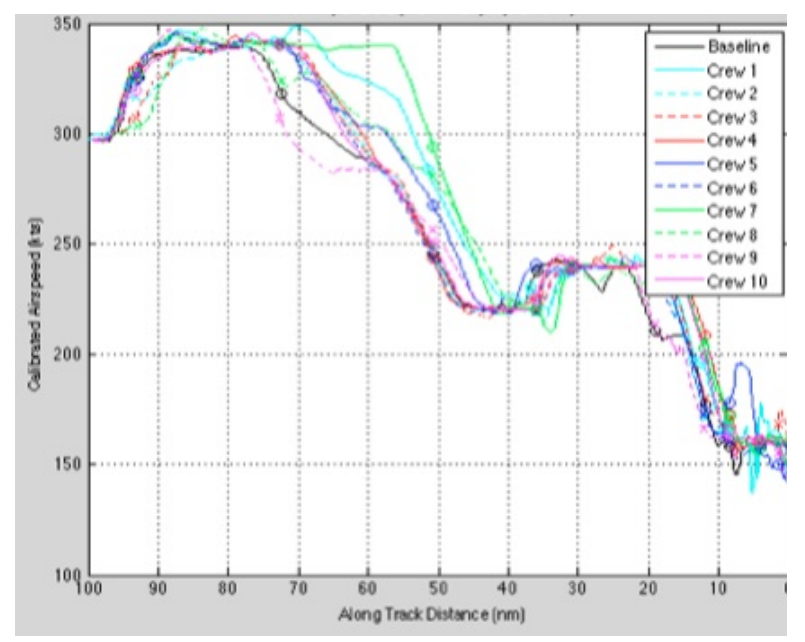

a) Scenario1

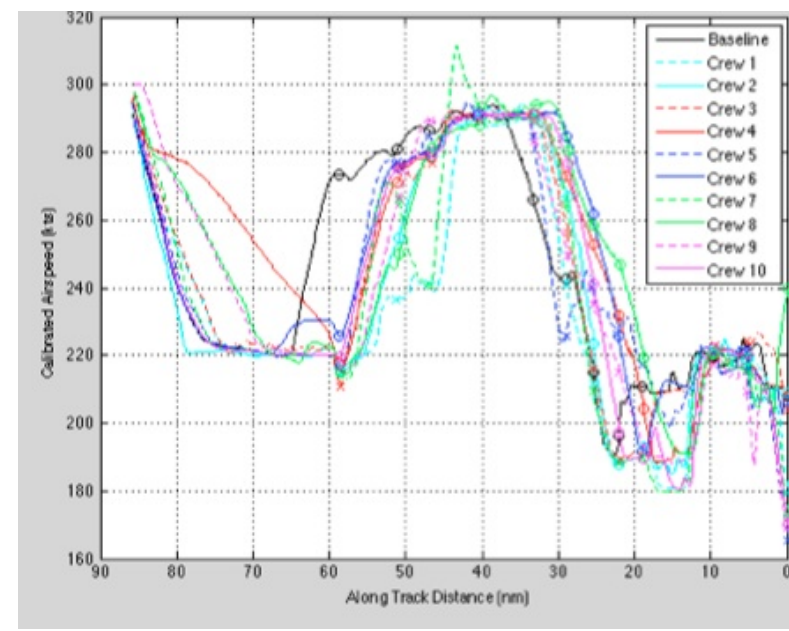

b) Scenario 7

Figure 3. Speed Profiles for 10 Crews and the Baseline Crew for Scenario1 and Scenario7 


\section{Reported Workload}

Since all the scenarios were feasible but varied in the time required to fly them, the degree of workload they imposed on the crew was explored. The real-time workload ratings, given every five minutes by both members of the crew during each run, were reviewed to explore whether there was any relationship between the study conditions and pilot perceived workload. Participants were prompted to rate their workload on a 1 to 7 scale (from "very low" to "very high") (see [11] for details), usually four times during a run. These ratings were separated into those given by the flying-pilot and those given by the non-flying pilot. Figure 4 shows the average workload reported by both the flying-pilot and the non-flying-pilot for each scenario.

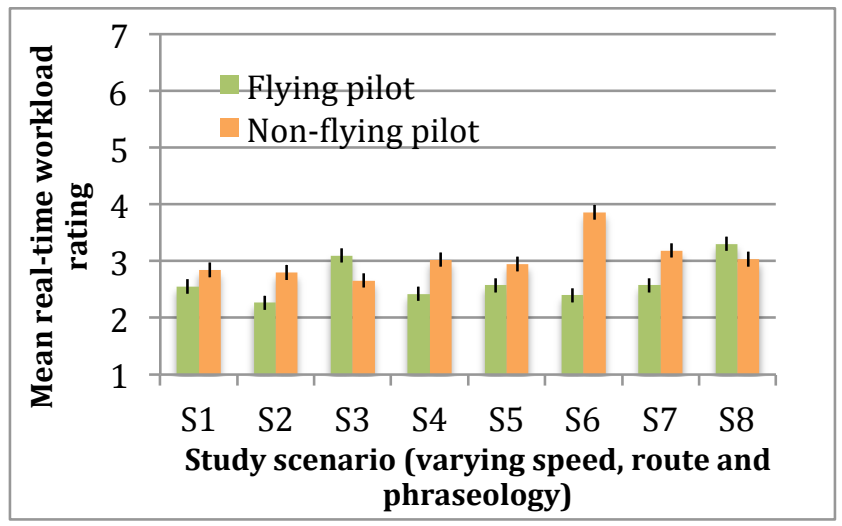

Figure 4. Mean Real-time Workload for Each Flying Position by Each Route (with Standard Error)

Over the whole study, workload was rated as "moderate to low" $(\mathrm{M}=2.82, \mathrm{SD}=1.39)$ and this is broadly true for each scenario, since all but one of the average ratings shown in Figure 4 is around 3 on the scale. On average, the non-flying pilot rated his/her workload as higher than that of the flying-pilot in six of the eight scenarios. Only Scenario3 and Scenario8 were rated as having more load on average by the flying-pilot. The only condition that these two scenarios share is the speed scheme - they both used the slow-to-fast scheme, suggesting that pilots may have had to manipulate the controls more actively when very slow at altitude and fast on final approach. The non-flying pilots' mean workload ratings do not show the same pattern as they tend to be higher for the RIIVR approaches than the SADDE approaches.
The workload data were re-sorted by the scenarios' speed scheme, i.e., workload for Scenarios $1,2,5$ and 6 were grouped and compared to the workload for Scenarios 3, 4, 7 and 8 (Figure 5). There is a significant difference in flying-pilots' workload ratings $(\mathrm{Z}=2.47, \mathrm{n}=138, \mathrm{p}=0.013)$ when tested using a Wilcoxon-Signed-Rank test, indicating that the flying pilot reported the slow-to-fast speed schemes generated more load for them $(\mathrm{M}=2.83)$ than the fast-to-slow schemes $(\mathrm{M}=2.44)$; although it must be noted that these mean load ratings are still "moderate to low". A review of the flying pilots' mean workload scores indicates they incurred higher workload especially in the last phase of the approach, as the final workload rating (out of 4) reported in three of the four scenarios produced a mean that is higher than those the pilots gave to the previous prompts in the run. There is no significant difference in the non-flying pilots' workload between the speed schemes.

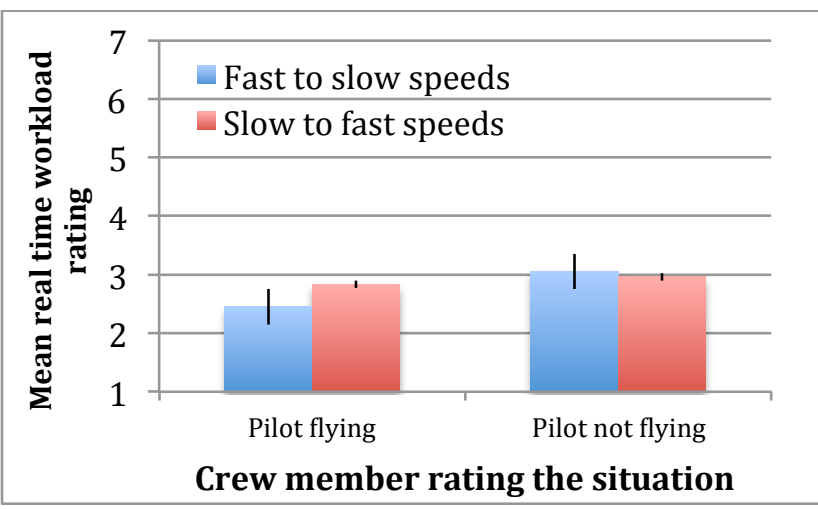

Figure 5. Mean Real-time Workload for Each Flying Position by Scenario Speed Scheme (with Standard Error)

To verify whether crews experienced different workload based on the speed scheme presented, the responses participants gave to the workload questions in their post-run questionnaire were sorted by the speed scheme of the run and an overall mean calculated. Four scales from the NASA TLX [12] were asked in the post-run questionnaire and participants responded on a 1-7 ("very low" to "very high") scale. Figure 6 illustrates that, post-hoc, participants responded more strongly that the slowto-fast speed scheme generated the most workload. They rated both the effort required and the time pressure they felt to be significantly higher in the 
slow-to-fast scheme (Zeffort \& Ztime pressure $=3.86$, $\mathrm{n}=80, \mathrm{p}=0.000$ ). However, they also felt more frustrated $(Z=2.97, n=80, p=0.003)$ but no less successful. Further supporting data comes from a fifth question that asked whether the speed changes issued in the scenario were reasonable. Participants rated the fast-to-slow speeds as more reasonable $(\mathrm{Z}=$ 2.46, $\mathrm{n}=80, \mathrm{p}=0.014$; Mfast-to-slow=4.6) than the slow-to-fast speed schemes $(\mathrm{M}=4)$.

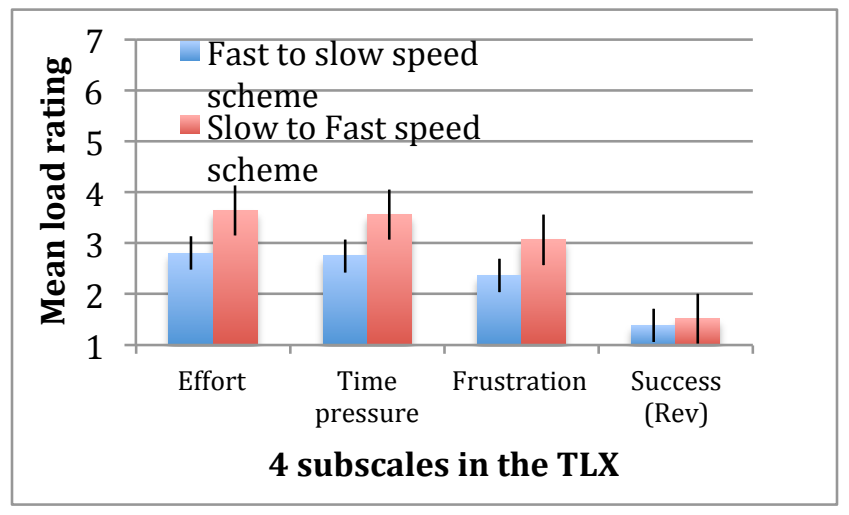

Figure 6. Mean Retrospective Workload by Scenario Speed Scheme (with Standard Error)

\section{Crew Responses to Speed Clearances}

Despite the higher load, very few crews refused clearances. In fact, only two crews refused a clearance (said "unable" as a response to an instruction). However, crews did express their unease in slightly less direct ways.

Table 1 below lists the relatively few responses that crews gave to clearances that were not simply read-backs and acceptances of the instruction. As noted, there were only two straight rejections of a clearance, when a crew did not read back the instruction but said they were "unable" to complete it. These were both during slow-to-fast speed schemes when the ATC asked the crew to slow to 220 knots above 10,000ft. However, this does not mean that crews did not experience some difficulty when flying the clearances. They queried or requested a modification to the clearance at least 25 times. Since there were 590 planned speed clearances given during the study, crews queried $4.2 \%$ of the instructions issued. A further $2.5 \%$ (15) of the clearances issued were accepted but later reported to be unobtainable.
Table 1. Crew Queries and Statements to ATC

\begin{tabular}{|l|c|}
\hline Communication & Count \\
\hline Unable & 2 \\
\hline $\begin{array}{l}\text { High/fast over way- } \\
\text { point }\end{array}$ & 15 \\
\hline Clarify / query & 14 \\
\hline Request a change & 5 \\
\hline Request different speed & 6 \\
\hline Other & 1 \\
\hline Total & $\mathbf{4 3}$ \\
\hline
\end{tabular}

Categorizing the queried clearances suggests there were three main ways that crews dealt with a clearance that was going to be problematic to execute. One method was to accept the clearance and then later tell the controller that they could not achieve one or more aspects of it, e.g., "We'll be a little high at SADDE". A second method was to query or clarify the clearance as it was given; and the third method was to request a different speed that was less extreme at the time the clearance was given. The first method worked the best for the crews - it is obviously impractical for the controller to ask them to meet an altitude when they were already flying over the waypoint. If it had been important for the airplane to meet the restriction, there would have been little the controller could have done to save the situation and, if the controller had been working to meet a schedule, it may have made this harder to achieve. With the second and third methods of requesting and suggesting different speeds, the controller would have been able to re-organize and re-strategize earlier if necessary.

In the debrief discussions, some crews described that a fourth way to offset the impact of the speed clearances was to achieve them slowly. They felt gradual acceleration and deceleration would be more acceptable to passengers and was easier for them to manage. This view was not shared by all crews; others said they would fly "however we need to to make it happen." These differences in strategies are apparent in Figure 3b above where crews who were trying to achieve speeds quickly and those who were trying to achieve them slowly resulted in as much as a 50 knot difference in IAS over some waypoints. It is differences like this in crew strategies that contribute to the three-minute variation in the timeto-fly the descent discussed above. 


\section{Discussion}

Of the four variables explored in this study, the speed manipulation seemed to have the greatest impact on crews' workload, based on their selfreports, and on their responses to the controllers' clearances. In debriefing discussions crews specifically cited the very slow "dirty" speeds above $20,000 \mathrm{ft}$ and the very fast speeds just before the outer marker as the most problematic clearances. While some said these extremes were "not unreasonable but not typical" others said they were "ridiculous". Crews had a variety of reasons for disliking the slow speed at altitude, including configuration management, care of the equipment and fuel efficiency. Others seemed to dislike the following clearance to increase speed rather than the initial slow speed clearance per-se, chiefly because they had to reconsider their earlier configuration decision. Crews disliked the fast-before-the-outer-marker speed because it was difficult to achieve a stabilized approach, as stated by company procedures, immediately after having to hold a fast speed. As company procedures differed, a "stabilized approach" was harder to achieve for some crews than others.

A general observation from this study is that "extreme" clearances, which issue large changes in speed, can be difficult to achieve and can substantially increase crew workload. If these speeds had been issued as part of a controller's efforts to meet a time-based schedule (rather than simply a manipulation of a percentage around the profile) there are examples in the study where the schedule could not have been met. However, crews accepted a surprising number of the "extreme" clearances with equanimity. The twenty-percent-faster clearances seemed generally acceptable, except during the last few miles of the descent; and slow speeds were more acceptable if they did not require a change in the aircraft's configuration. While these findings do not provide a definitive scheme to assist researchers developing schedule-based algorithms and controller DSTs, they do suggest some key factors that, if taken into consideration may make some "extreme" clearances more likely to be accepted.

A second finding was a large variation in the way crews flew the descents. The variation observed in this study may have important implications for the design of the ground decision support tools, suggesting that tolerance for this variability may need to be accounted for the in descent profile calculations for the ground automation. In this simulation, this finding is summarized by the descent times, which varied by almost three minutes on the RIIVR route. Variations in descent times are the result of many factors that differed across the ten crews who participated: company procedures, personal flying style, strategies, and understanding of both energy management in general and the specific airplane FMS in particular. For example, some crews chose to stay in an automated mode when they were flying (LNAV and VNAV) while others chose to fly with a lower level of automation (FLCH), some used speed brakes more readily than others, and some retracted their flaps after they had been deployed while others did not.

\section{Comments on Study Focus}

The key aim of this study was to explore the flight-crew-related assumptions inherent in the ATD1 concept [1]. These were three-fold: crews could fly the descents, workload would not increase, and no training is required. Although it was clear that flying these RNAV OPDs was feasible, crews did question the efficiency of a descent with multiple speed changes that required alternate uses of thrust and braking techniques. Thus, from an efficiency perspective, speed adjustments that remain closer to the nominal profile will be preferable to flight-crews.

A degree of doubt was cast over the assumption that flight crew workload will not be impacted. While the load caused by the "extreme" speed clearances cannot be extracted from the results, there are some indications that general workload could be affected even by speeds closer to the profile. Observers noted crews needed to interact frequently with the FMS (to enter the waypoint speeds on the LEGS page) if they wanted the aircraft to stay on, and recalculate, the vertical profile of the descent. This activity possibly accounts for the higher workload ratings given by the non-flying pilot (when compared to the flying pilot) in three quarters of the Scenarios (shown in Figure 4). Crew procedures also contributed to this load if they specified that every altitude constraint at a waypoint had to be dialed into the Mode Control Panel, rather than dialing it down to the lowest cleared altitude. Studies to specifically compare crew workload under different procedures and to compare workload on current day step-down 
profiles with OPDs will shed light on the degree to which CMS impacts flight crew workload.

Crews were divided in their opinions of whether training is necessary to fly schedule-based OPDs, with the majority agreeing that a flight bulletin would be sufficient. However, observing across all ten crews showed that, although everyone could achieve the descents, some crews achieved them far more efficiently than others. Further analysis of the data is underway to describe crew styles and relate them to the quantifiable data but, at a very general level, it was observed that crews who used the automation more fully and effectively seemed less time pressured and more "ahead of the airplane". It may be that while crews do not require specific training on managing OPDs, more general training on FMS management and utilization would be beneficial.

\section{Conclusion}

This exploratory study was valuable as it establishes that the impacts of a schedule-based, controller managed concept on the current day (nonFIM) flight-deck need to be considered as a part of the ATD1 research. It highlighted a number of variables that were considered that need closer investigation (e.g., constraints on speed parameters, interpretation of conditional phraseology in clearances), and uncovered some additional variables that need to be studied (best procedures for OPDs, training requirements). The observations indicated that some flight crews could manage large variations in speed instructions and effectively manage the aircraft automation to absorb some of the redistributed/ increased workload, but not all. The most striking finding was the large variation in crews' performance and, although some of this variation could be addressed through specific procedures and crew training, the importance of automation and time-based schedules having enough flexibility to absorb aircraft-by-aircraft variations was underlined.

\section{References}

[1] Robinson III, J. E., 2011, Air Traffic Management Technology Demonstration-1 (ATD-1): Interval Management-Terminal Area Precision Scheduling System Demonstration Description and Plan, Version 2.5, NASA Ames Research Center, CA, October 6.
[2] Swenson, H., J. Thipphavong, A. Sadovsky, L. Chen, C. Sullivan, \& L. Martin, 2011, Design and Evaluation of the Terminal Area Precision Scheduling and Spacing System, Proceedings of the Ninth USA/Europe Air Traffic Management Research and Development Seminar (ATM2011), Berlin, Germany, June.

[3] Isaacson, D., J. Robinson III, H. Swenson, \& D. Denery, 2010, A concept for robust, high density terminal air traffic operations, $10^{\text {th }}$ AIAA Aviation Technology, Integration, and Operations (ATIO) Conference, Fort Worth, TX.

[4] Prevôt, T., P. Lee, T. Callantine, J. Mercer, J. Homola, N. Smith, \& E. Palmer, 2010, Human-inthe-Loop Simulation of NextGen Concepts in the Airspace Operations Laboratory, Proceedings of the AIAA Modeling and Simulation Technologies Conference, AIAA-2010-7609, Toronto, Ontario.

[5] Kupfer, M., T. Callantine, L. Martin, J. Mercer \& E. Palmer. 2011, Controller support tools for schedule-based terminal-area operations, Proceedings of the Ninth USA/Europe Air Traffic Management Research and Development Seminar (ATM2011), Berlin, Germany, June.

[6] Callantine, T., E. Palmer \& M. Kupfer, 2010, Human-in-the-loop simulation of trajectory based terminal-area operations, $27^{\text {th }}$ International Congress of the Aeronautical Sciences (ICAS), Nice, France.

[7] Prevôt T., 2012, How to compute a slot marker calculation of Controller Managed Spacing tools for efficient descents with precision scheduling, Proceedings of the 31st Digital Avionics Systems Conference (DASC2012), Williamsburg, VA, to appear, October 14-18.

[8] Murdoch, J., B. Barmore, B. Baxley, T. Abbott, \& W. Capron, 2009, Evaluation of an Airborne Spacing Concept to Support Continuous Descent Arrival Operations, Proceedings of the 8th USA/Europe Air Traffic Management Research and Development Seminar (ATM2009), Napa, CA, June.

[9] Sullivan, B.T., P.A. Soukup, 1996, The NASA 747-400 flight simulator: A national resource for aviation safety research, AIAA-96-3517-CP, American Institute of Aeronautics and Astronautics, San Diego, CA, July 29-31, pp. 374-384.

[10] Prevôt, T., P. Lee, T. Callantine, J. Mercer, J. Homola, N. Smith \& E. Palmer, 2010, Human-in-the- 
loop evaluation of NextGen concepts in the Airspace Operations Laboratory, AIAA 2010-7609, American Institute of Aeronautics and Astronautics, Reston, VA.

[11] Stein, E.S., 1985, Air traffic controller workload: An examination of workload probe (DOTIFAA/ CT-TN84124), Atlantic City International Airport, NJ, Federal Aviation Administration Technical Center.

[12] Hart, S. \& L. Staveland, 1988, Development of the NASA-TLX (Task Load Index): Results of empirical and theoretical research. In P. Hancock \& N. Meshkati (Eds.), Human mental workload, Amseterdam, North Holland, pp. 139-183.

\section{Acknowledgements}

Thank you to the CVSRF development team at NASA Ames Research Center and the pilot subject matter experts without whom this study could not have been completed.

\section{Email Addresses}

Lynne.Martin@nasa.gov

Sandra.C.Lozito@,nasa.gov

31st Digital Avionics Systems Conference

October 14-18, 2012 